\title{
Análisis General del Desarrollo e Implementación de los Mecanismos Alternativos de Solución de Controversias en México, de Cara al Siglo XXI
}

\section{Lourdes Guadalupe Serrano Muñoz ${ }^{1}$}

Sumario: Introducción II. Mediación III. Las Consultas IV. La Transacción Intraprocesal V. Arbitraje VI. Conclusión

\section{Resumen}

El aparato jurisdiccional mexicano se ha caracterizado por la resolución de conflictos en un tiempo mayor a lo que la sociedad y la economía nacional necesita. Además, en ocasiones los fallos obtenidos resultan injustos para quienes instaron a los jueces. Este último punto es entendible, pues no existen mejores personas para entender un problema que las que lo están padeciendo. Sin embargo, no es lo que los justiciables desean.

En ese sentido, el propósito de este ensayo es explicar de manera breve algunas características de los principales mecanismos alternos de solución de controversias que se encuentran vigentes en la legislación mexicana, así como destacar la necesidad y efectividad que prometen para el futuro del país.

\section{Abstract}

The Mexican judicial apparatus has been characterized by the resolution of conflicts in a time greater than what the society and the national economy needs. In addition, sometimes the judgments obtained are unfair to those who urged the judges. This last point is understandable, because there are no better people to comprehend a problem than those who are suffering. However, it is not what the people want.

\footnotetext{
${ }^{1}$ Docente Investigadora indeterminada del Departamento de Derecho de la DCS,URC de la Universidad de Sonora
} 
In this sense, the purpose of this essay is to briefly explain some characteristics of the main alternative dispute resolution mechanisms that are in force in Mexican legislation, as well as to emphasize the necessity and effectiveness that they promise for the future of the country.

\section{Introducción}

En México, el artículo 17 de la Constitución General de la República actualmente establece en su cuarto párrafo que "Las leyes preverán mecanismos alternativos de solución de controversias." Dicho texto denota la voluntad del Constituyente permanente para responder a la problemática que invade a nuestra sociedad actualmente.

La consagración y establecimiento de dicho texto en nuestra Carta Magna de los mecanismos alternativos de solución de conflictos responde —en un aspecto orgánico — a la necesidad de mitigar un poco los problemas de acceso a la justicia y descargar un poco al sistema institucional (predominantemente que ejercen funciones materialmente jurisdiccionales).

Sin embargo, el crecimiento de la instauración de medios alternativos -en algunos Estados- estuvo relacionada con el aumento de la conflictividad social y la inoperancia y desbordamiento de los órganos formales de impartición de justicia.

Así, el empleo de mecanismos alternativos encuentra su justificación como una respuesta a la necesidad de componer los litigios de una manera más justa, sin formulismos ancestrales o tecnicismos injustificados que, en vez de cumplir con el propósito para el que se han establecido en los procedimientos judiciales, sirven para dilatar los procesos y evitan llegar a una solución en un plazo razonable. 
Como respuesta a la exigencia tanto social como constitucional, en Sonora se emitió la Ley número 161 llamada "Ley de Mecanismos Alternativos de Solución de Controversias para el Estado de Sonora", en la cual se han acogido principios y reglas reconocidas por estándares internacionales., cuyo artículo $1^{\circ}$ es ejemplo de lo que se viene refiriendo, pues establece que:

La presente Ley es de orden público y de interés social en el Estado y tiene por objeto promover y regular los mecanismos alternativos de solución de controversias, así como a los centros que brinden estos servicios a la población y la actividad que desarrollen los prestadores de dichos servicios.

Los habitantes del Estado de Sonora tienen el derecho de resolver sus controversias de carácter jurídico a través de vías colaborativas en las que se privilegie el diálogo y, el Estado el deber de proporcionar y promover los mecanismos para que lo logren pacíficamente, conforme a los principios y disposiciones de la presente Ley.

Asimismo, dicha ley no tiene como fin limitar o restringir el acceso a la justicia, sino todo lo contrario. Previene al ciudadano con la opción de resolver su conflicto ante instancias menos formales y posiblemente más rápidas y justas, que convengan más a sus intereses. La opción se ha establecido claramente en el artículo 3 de la citada ley al explicar que los mecanismos alternativos de solución de controversias son eso, alternativos a la jurisdicción y competencia de los tribunales del Estado.

\section{Mediación}

Uno de los mecanismos que se han establecido en diversas entidades de nuestro país, es la mediación.

La mediación — para Christopher Moore— es la intervención en una 
disputa o negociación, de un tercero aceptable, imparcial y neutral que carece de un poder autorizado de decisión para ayudar a las partes en disputa a alcanzar voluntariamente su propio arreglo mutuamente aceptable. $^{2}$

Asimismo, el artículo 2, fracción IV de la ley estatal, define a la mediación como "[el] proceso voluntario en el cual un profesional imparcial y sin facultad para sustituir las decisiones de las personas involucradas en una controversia, las asiste con la finalidad de facilitar las vías de diálogo y la búsqueda en común de un acuerdo".

Lo que caracteriza a este medio alternativo es la inclusión de un extraño que no tiene poder para tomar decisiones en nombre de las partes. Su intervención —de acuerdo al postulado de Linda R. Singeres para "devolver las aguas a su cauce mediante diversos métodos", los cuales se reseñan a continuación:

- Suavizar los ánimos encrespados.

- Actuar como guía imparcial de la discusión y asegurar que todas las partes tengan oportunidad de hablar.

- Ayudar a diferenciar intereses de posiciones.

- Trabajar con las partes para idear soluciones creativas que cubran sus respectivas necesidades.

- Ganarse la confianza de las partes, de modo que compartan con él información confidencial sobre sus intereses y alternativas.

- Trasladar de uno a otro una selección de la información, traduciéndola de un lenguaje negativo a uno positivo.

- Actuar como un representante de la realidad y ayudar a las partes a ser más realistas con respecto a sus alternativas.

- Ofrecer, ocasionalmente, una opinión objetiva sobre el aspecto

\footnotetext{
${ }^{2}$ MOORE, Christopher, El proceso de mediación, Primera edición, Buenos Aires, Granica, 2006, pág. 44.
} 
positivo de la controversia.

- Mantener viva la negociación cuando las partes están dispuestas a abandonar.

- $\quad$ Efectuar recomendaciones, si las partes lo piden.

- Actuar de "cabeza de turco"3 cuando las cosas van mal.

Por otro parte, con fines enunciativos, es importante destacar que los principios que deben regir a este y todo tipo de mecanismo alternativo, son los de voluntariedad, confidencialidad, buena fe y veracidad, neutralidad, imparcialidad, equidad, legalidad, honestidad, flexibilidad, oralidad, consentimiento informado e intervención mínima, los cuales serán materia de un análisis más profundo en el desarrollo de este ensayo.

\section{Las consultas}

De acuerdo a la Organización Mundial de Comercio (OMC), las consultas bilaterales son la primera etapa del sistema formal de solución de diferencias, pues dan a las partes la oportunidad de debatir la cuestión y encontrar una solución satisfactoria sin recurrir al litigio.

El Entendimiento Relativo a las Normas y Procedimientos por los que se Rige la Solución de Diferencias (ESD), emitido por la OMC, es el fundamento de las citadas consultas. Dicho medio alternativo de solución de controversias ha sido benéfico para las partes integrantes de la OMC pues la mayoría de los conflictos no han pasado de la etapa de consultas, por haberse encontrado una solución satisfactoria o porque simplemente se decidió por el reclamante no seguir adelante con su demanda.

Entonces, las consultas son el principal instrumento no

\footnotetext{
${ }^{3}$ Chivo expiatorio, es decir, asumir la culpa de las cosas que van mal en la negociación.
} 
judicial/diplomático del sistema de solución de controversias de la OMC. Las consultas permiten que las partes esclarezcan los hechos del asunto y las alegaciones del reclamante, disipando posiblemente los equívocos en cuanto a la naturaleza real de la medida en litigio. En este sentido, las consultas sirven para sentar las bases de una solución o para llevar adelante el procedimiento con arreglo al ESD.

\section{La transacción intraprocesal}

El ámbito propiamente jurisdiccional no es totalmente ajeno a los mecanismos alternativos, pues en muchas legislaciones se contempla el sistema autocompositivo denominado "transacción intraprocesal", el cual se conoce comúnmente como "convenio judicial".

La transacción intraprocesal es un convenio por medio de la cual las partes haciendo reciprocas concesiones, van a tratar de resolver sus diferencias o evitar una futura. En un proceso judicial, las partes son las que comparecen a proponer la solución del conflicto, cuyo acuerdo tiene que ser ratificado ante la presencia judicial, a no ser que se haya celebrado ante fedatario público. ${ }^{4}$ Una vez que el juez aprueba la legalidad del contenido, este acuerdo tiene efectos de sentencia ejecutoriada.

Abundando al respecto, en el ámbito local, los artículos 3395, 3396 y 3398 del Código Civil para el Estado de Sonora definen al contrato de transacción y sus consecuencias ante la instancia judicial, pues establecen lo siguiente:

\footnotetext{
${ }^{4} \mathrm{La}$ excepción a la regla que establece que debe ser siempre ratificado ante la presencia judicial, y prevé que sea posible realizar dicha ratificación ante fedatario, ha sido determinado por la Primera Sala de la Suprema Corte de Justicia de la Nación, cuyo rubro reza "CONTRATO DE TRANSACCIÓN RATIFICADO ANTE NOTARIO PÚBLICO Y AJUSTADO A DERECHO. CUANDO SE EXHIBE PARA DAR POR TERMINADO EL JUICIO, ES INNECESARIO EMPLAZAR A LA PARTE DEMANDADA PARA QUE EL JUEZ PUEDA APROBARLO".
} 


\begin{abstract}
ARTICULO 3395. La transacción es un contrato por el cual las partes, haciéndose recíprocas concesiones, terminan una controversia presente, o previenen una futura, determinando con exactitud el alcance de sus derechos, que deben ser, para que exista este negocio jurídico, dudosos o inciertos en cuanto a su existencia, validez, exigibilidad o cuantía.
\end{abstract}

ARTICULO 3396. Cuando la transacción ponga término a una controversia judicial tendrá un carácter mixto: como contrato civil y como acto jurisdiccional, para sujetarse, respectivamente, a las normas que regulan los contratos, la transacción en especial y los actos procesales en cuanto a la competencia del juez y la capacidad de las partes para comparecer en juicio.

ARTICULO 3398. Cuando la transacción de término a una controversia judicial, deberá constar por escrito y ratificarse en la presencia del juez o miembros que integren el tribunal, quienes deberán cerciorarse de la identidad y capacidad de la partes. Si dicha transacción se refiere a bienes inmuebles 0 derechos reales susceptibles de registro, deberá ordenarse su inscripción en el Registro Público, para que surta efecto en perjuicio de tercero.

Entonces, el artículo 3395, establece que por transacción debe entenderse el contrato por el cual las partes, haciéndose recíprocas concesiones, terminan una controversia presente o previenen una futura; por su parte, el diverso artículo 3406 del referido Código Civil previene que la transacción tiene, respecto de las partes, la misma eficacia y autoridad que la cosa juzgada.

Ahora bien, al ser esencial que este tipo de contrato sea bilateral, como consecuencia necesaria de la reciprocidad de concesiones que se hacen las partes, lo que supone la existencia o incertidumbre de un derecho dudoso, de un derecho discutido o susceptible de serlo, y que origine obligaciones de dar, hacer o no hacer que correlativamente se imponen los contratantes, pues precisamente su objeto es el de realizar 
un fin de comprobación jurídica, esto es, de establecer la certeza en el alcance, naturaleza, cuantía, validez y exigibilidad de derechos, cuando se celebra, las personas que en dicho contrato intervienen están obligadas a lo expresamente pactado. Es por lo anterior que lo establecido en el Código de Procedimientos Civiles para el Estado de Sonora, cuando previenen que la vía de apremio procede a instancia de parte cuando se trate de la ejecución de una sentencia y que todo lo dispuesto en relación con la sentencia comprende los convenios judiciales y las transacciones, las cuales deberán ser de aquellas que ponen fin a una controversia presente o previenen una futura, controversia que forzosa y necesariamente debe existir, es aplicable al contrato de transacción, pues reúne las condiciones apuntadas, y ante ello es claro que puede exigirse su cumplimiento en la vía de apremio.

Lo anterior denota la obligatoriedad del pacto intraprocesal, que acaba con un proceso lento y prolongado, por una solución rápida que no admite duda alguna, sino que únicamente las partes se someten a lo acordado en dicho acuerdo.

\section{Arbitraje}

El arbitraje nace ante la necesidad o voluntad de evadir el sometimiento a un tribunal jurisdiccional estatal. Para ello, se firma un acuerdo arbitral que implica para las partes la renuncia a su derecho de accionar ante el tribunal nacional para que éste solucione el litigio y, a su vez, impide a los tribunales jurisdiccionales ejercer la función jurisdiccional sobre litigios precisados por las partes, conduciéndolas a dirimir su controversia a través del proceso arbitral. $^{5}$

\footnotetext{
${ }^{5}$ Lo anterior es sin perjuicio de la postestad estatal de impedir la justicia por mano propia, obligando la ejecución de los laudos a través de su imperio.
} 
Cabe señalar que en la actualidad, el sistema jurídico mexicano ha tenido aciertos y desaciertos sobre el tema, pues existe la decisión de la contradicción de tesis 51/2005-PS de la Primera Sala de la Suprema Corte de Justicia de la Nación, donde decidió que

La posibilidad de apartar la intervención de la justicia estatal en un conflicto, a fin de someterlo al arbitraje comercial, es una manifestación de la potestad de los particulares para renunciar a sus derechos subjetivos y establecer los dispositivos legales a los cuales desean someterse; de ahí que un acuerdo de arbitraje pueda estar incluido en un contrato como cláusula compromisoria, lo que por regla general y en términos del artículo 1432 del Código de Comercio, otorga su competencia a los árbitros para intervenir, conocer y decidir aun sobre la existencia o validez del propio contrato, así como de dicha cláusula compromisoria, lo contrario violaría la voluntad de las partes. Sin embargo, existe una excepción a dicha regla, cuando en términos del artículo 1424 del citado Código, ante un órgano jurisdiccional se somete el diferendo, sobre un contrato que contenga una cláusula compromisoria, y se ejerza al mismo tiempo la acción para que la misma se declare nula, ineficaz o de ejecución imposible, la que en dicho supuesto haría necesaria una decisión judicial previa, sobre la acción de nulidad. Lo anterior porque, por un lado, no debe soslayarse la existencia del debido control judicial sobre el arbitraje y, por el otro, la competencia de los árbitros proviene de la autonomía de la voluntad de las partes, de manera que si se alega, por ejemplo, la existencia de algún vicio de la voluntad en el acto que otorga competencia al árbitro, la acción de nulidad debe resolverse previamente por el órgano jurisdiccional, quedando a salvo los derechos de las partes para que en términos del segundo párrafo del referido artículo 1424 puedan iniciarse las actuaciones arbitrales relativas a la disputa sobre el cumplimiento e inclusive la existencia o validez del propio contrato que contiene la cláusula compromisoria, ya que a ese respecto el tribunal arbitral conserva su competencia exclusiva. ${ }^{6}$

${ }^{6}$ ARBITRAJE COMERCIAL. COMPETENCIA PARA CONOCER DE LA ACCIÓN DE NULIDAD DEL ACUERDO DE ARBITRAJE PREVISTA EN EL PRIMER PÁRRAFO DEL ARTÍCULO 1424 DEL CÓDIGO DE COMERCIO, CORRESPONDE AL JUEZ Y NO AL TRIBUNAL ARBITRAL. [J]; 9a. Época; 1a. Sala; S.J.F. y su Gaceta; Tomo XXIV, Septiembre de 2006; Pág. 5. 
De lo anterior denota un análisis previo de legalidad, demostrando una vez más el Estado su imperio sobre cualquier arreglo comercial, lo que algunos consideran que debe prevalecer y otros no. Incluso, los ministros Olga María Sánchez Cordero de García Villegas y José Ramón Cossío Díaz emitieron un voto de minoría, al no estar conformes con lo decidido por la mayoría de dicha sala, y se pronunciaron, llegando a la siguiente conclusión:

De tal forma que toda resolución emitida por Jueces o tribunales estatales que recaiga sobre cuestiones que no sean propiamente de orden o interés público y que, además, hayan sido explícitamente encomendadas al poderío exclusivo de un determinado árbitro o tribunal arbitral, incluyendo toda cuestión relativa a la validez, nulidad o inexistencia de la cláusula compromisoria o compromiso arbitral, acabaría violentando el principio de autonomía de la voluntad de las partes, de modo tan alarmante, que se vería pisoteado tanto su sano albedrío como la razón de existencia de todo procedimiento, medio o instrumento alterno que intente de manera justa, viable y eficaz dar solución al sinnúmero de conflictos que se suscitan en el creciente tráfico de negocios y servicios en la sociedad de hoy.

Así, en el mundo -y de manera gradual en México- ha imperado el arbitraje como forma alternativa de solucionar conflictos.

Para Antonio Garza Canovas, el arbitraje es el medio más eficaz para resolver las controversias derivadas de las relaciones comerciales internacionales. ${ }^{7}$

Sin embargo, agregando a lo que el autor en cita postula, el arbitraje ha

\footnotetext{
7 GARZA CANOVAS, Antonio, La Convención Interamericana sobre Arbitraje Comercial Internacional: un paso firme [Texto en PDF], Garza Casanovas Antonio (Revista de Derecho Privado, Número 5, Sección de Previa, 1991) (revisado el 01/10/2013). Obra consultable en: http://biblio.juridicas.unam.mx/estrev/pdf/derint/cont/8/rse/rse32.pdf
} 
resultado el medio más efectivo para resolver controversiales comerciales tanto nacionales como internacionales.

Al respecto, en materia internacional regional, se cuenta con la Convención Interamericana Sobre Arbitraje Comercial Internacional, cuyo artículo primero establece que Es válido el acuerdo de las partes en virtud del cual se obligan a someter a decisión arbitral las diferencias que pudiesen surgir o que hayan surgido entre ellas con relación a un negocio de carácter mercantil. El acuerdo respectivo constará en el escrito firmado por las partes o en el canje de cartas, telegramas 0 comunicaciones por telex.

En el ámbito internacional ampliado, con el propósito de unificar el tratamiento jurídico de la cláusula compromisoria y del compromiso arbitral, la Convención de Nueva York de 10 de junio de 1958, relativa al reconocimiento y ejecución de las sentencias arbitrales, en su artículo segundo, numeral primero, establece que Cada uno de los Estados contratantes reconocerá el acuerdo por escrito conforme al cual las partes se obliguen a someter a arbitraje todas las diferencias o ciertas diferencias que hayan surgido o puedan surgir entre ellas respecto a una determinada relación jurídica, contractual o no contractual, concerniente a un asunto que pueda ser resuelto por arbitraje. Asimismo, en su subsecuente numeral segundo, ordena que La expresión 'acuerdo por escrito' denotará una cláusula compromisoria incluida en un contrato o un compromiso, firmados por las partes o contenidos en un canje de cartas o telegramas.

Así, de las convenciones aludidas, sin importar la posible diferenciación conceptual que pueda existir entre una cláusula compromisoria y un compromiso arbitral, se aprecia que ambos conceptos persiguen un mismo fin, esto es, permitir que ciertas y determinadas o determinables 
controversias puedan ser resueltas por un árbitro o tribunal arbitral designado por las partes

Con fines ilustrativos, se menciona que la Ley de Mecanismos Alternativos de Solución de Controversias para el Estado de Sonora, en su artículo 5, segundo párrafo, establece que el arbitraje se sujetará a lo dispuesto en el Código de Procedimientos Civiles para el Estado de Sonora, cuyo procedimiento se encuentra establecido en el Título Noveno de dicha legislación adjetiva.

\section{Conclusión}

En los tiempos actuales, el crecimiento demográfico, la concentración de la población y el aumento del tráfico de negocios y servicios han llegado a tal grado que el Estado se ha visto en la necesidad de permitir la posibilidad de instaurar ciertos procedimientos alternos que resuelvan determinados conflictos que se suscitan en la sociedad.

Así, la creación de estos procedimientos como medios e instrumentos alternos para la solución de controversias se ha debido a la noción del Estado en el sentido de que la acción de administrar e impartir justicia es una atribución establecida en aras de satisfacer el interés y la protección de los particulares, puesto que su finalidad primordial es garantizar pródigamente el acceso a la justicia de sus gobernados. Por ello, no debe entenderse que tal atribución de administrar e impartir justicia es única y exclusiva de los jueces o tribunales estatales, pues la legislación nacional e internacional instituye el derecho de los particulares de someter determinados conflictos a alguno de los referidos procedimientos alternos de solución de controversias, siempre que éstas no impliquen cuestiones propiamente de orden o interés público. 
En efecto, la resolución que pone fin al conflicto en un procedimiento arbitral no deriva propiamente de tribunales o Jueces estatales, sino de aquel sujeto de derecho privado, tercero e imparcial al negocio, que es elegido voluntariamente por las partes, a través de un acuerdo por escrito mediante el cual deciden desplazar, total o parcialmente, la potestad del Estado a aquel elegido que es denominado árbitro o tribunal arbitral para que conozca del asunto y resuelva determinadas 0 determinables controversias derivadas del mismo.

Cabe precisarse que el arbitraje requiere necesariamente para su sustanciación la expresión de la voluntad de las partes, pues si no existe ésta mediante acuerdo arbitral, por escrito, donde se manifieste su intención de someter determinada o determinable disidencia al poderío de un árbitro o tribunal arbitral designado, no es posible admitir la practicidad de dicho medio o instrumento alterno para solución de tales controversias.

En este orden de ideas, se concluye que el arbitraje es el mecanismo de resolución de controversias ideal para la situación actual de nuestro país, por la costumbre que se tiene arraigada de que "alguien decida nuestros problemas por nosotros", pero cuya evolución puede $-\mathrm{y}$ debería- desembocar en la instauración de procedimientos de mediación como regla general, y excepcionalmente la comparecencia a procesos arbitrales, y mucho menos a procedimientos jurisdiccionales.

\section{Bibliografía}

GARZA CANOVAS, Antonio, La Convención Interamericana sobre Arbitraje Comercial Internacional: un paso firme [Texto en PDF], Garza Casanovas Antonio (Revista de Derecho Privado, Número 5. Sección de Previa, 1991) (revisado el 01/10/2013). Obra consultable en: http://biblio.juridicas.unam.mx/estrev/pdf/derint/cont/8/rse/rse32.pdf 
MOORE, Christopher, El proceso de mediación, Primera edición, Buenos Aires, Granica, 2006

SILVA, Jorge Alberto, Arbitraje comercial internacional en México, Primera edición, Pereznieto Editores, S.A. de C.V.

Legislación y otros medios

Jurisprudencia y tesis (IUS)

http://ius.scjn.gob.mx/paginas/tesis.aspx

Código de Comercio

Código Civil del Estado de Sonora

Código de Procedimientos Civiles del Estado de Sonora

Constitución Política de los Estados Unidos Mexicanos 